\title{
Las bases geográficas de la lengua vehicular del imperio inca
}

Les bases géographiques de la langue véhiculaire de l'empire Inca

The geographical bases of the lingua franca of the Inca Empire

\section{César Itier}

\section{(2) OpenEdition}

\section{Journals}

Edición electrónica

URL: http://journals.openedition.org/bifea/8030

DOI: $10.4000 /$ bifea. 8030

ISSN: 2076-5827

Editor

Institut Français d'Études Andines

Edición impresa

Fecha de publicación: 1 agosto 2013

Paginación: 237-260

ISSN: 0303-7495

Referencia electrónica

César Itier, «Las bases geográficas de la lengua vehicular del imperio inca », Bulletin de l'Institut français d'études andines [En línea], 42 (2) | 2013, Publicado el 08 agosto 2013, consultado el 05 noviembre 2020. URL : http://journals.openedition.org/bifea/8030 ; DOI : https://doi.org/10.4000/ bifea.8030

\section{(2) $(\Theta \Theta \Theta$}

Les contenus du Bulletin de l'Institut français d'études andines sont mis à disposition selon les termes de la licence Creative Commons Attribution - Pas d'Utilisation Commerciale - Pas de Modification 4.0 International. 


\title{
Las bases geográficas de la lengua vehicular del imperio inca
}

\author{
César Itier*
}

\section{Resumen}

El presente artículo reconsidera la tesis aceptada por varios lingüistas según la cual la lengua vehicular del imperio inca se originó en un dialecto quechua hoy extinto que se hablaba en la costa central peruana. En base a un examen de las fuentes históricas y de las evidencias filológicas, se muestra que no se habló quechua en la costa antes de la dominación inca y que la lengua vehicular del Tahuantinsuyo tiene su fuente en la variedad de quechua que se hablaba en el Cuzco. Esta variedad no debe confundirse con el dialecto cuzqueño tal como se observa desde fines del siglo XVI hasta la actualidad. En efecto, el quechua cuzqueño sufrió profundas transformaciones durante el siglo XVI al ser aprendido por la numerosa población que los incas habían instalado en el Cuzco y los valles aledaños.

Palabras claves: quechua, inca, lengua general, Cuzco, lingüística, dialectología

\section{Les bases géographiques de la langue véhiculaire de l'empire Inca}

\section{Résumé}

Cet article réfute la thèse souvent admise par les linguistes selon laquelle la langue véhiculaire de l'empire inca aurait eu sa source dans un dialecte quechua aujourd'hui éteint qui aurait été parlé sur la côte centrale du Pérou. Un examen des sources historiques et des premières attestations de la langue montre au contraire que le quechua n'était pas parlé sur la côte avant la domination inca et que la langue véhiculaire de l'empire procédait de la variété de quechua qui était parlée à Cuzco. Celle-ci ne doit pas être confondue avec le dialecte cuzquénien tel qu'on I'observe à partir de la fin du XVle siècle.

Profesor en el Institut National des Langues et Civilisations Orientales (INALCO) e investigador del Centre de Recherche et de Documentation des Amériques (CREDA-Institut des Hautes Etudes de I'Amérique Latine), París. E-mail: cesar.itier@gmail.com 
En effet, ce dialecte a subi de profondes transformations en étant appris par les nombreux groupes étrangers que les Incas avaient installés à Cuzco et dans les vallées alentours.

Mots clés : quechua, inca, langue générale, Cuzco, linguistique, dialectologie

\title{
The geographical bases of the lingua franca of the Inca Empire
}

\begin{abstract}
This article challenges the generally held theory that claims that the lingua franca of the Inca empire had its origin in a now extinct Quechuan dialect which was believed to have been spoken on the central coast of Peru. The study of the historical sources and the first written traces of this language show that the Inca lingua franca had its origin in the variety of Quechua spoken in Cuzco. This variety must not be confused with the Cuzco dialect such as we know it from the end of the 16th century. This dialect has undergone deep transformations as it was learnt by numerous foreign groups which the Incas had settled in Cuzco and in the surrounding valleys
\end{abstract}

Key words: quechua, inca, lingua franca, Cuzco, linguistics, dialectology

A inicios de la década de 1960, Gary Parker y Alfredo Torero publicaban sus respectivos ensayos de clasificación genética de los dialectos quechuas, que constituyen los trabajos fundadores de la lingüística andina. En estos, ambos autores mencionaban la existencia de un dialecto quechua costeño hoy extinto pero documentado por Domingo de Santo Tomás en su Lexicón y su Grammatica publicados en Valladolid en 1560 (Parker, 1963: 249; Torero, 1964: 475). En estudios posteriores, Alfredo Torero atribuyó a ese dialecto costeño un papel importante en la difusión del quechua: mediante el comercio a larga distancia, el quechua «yunga» se habría propagado tanto hacia los Andes del norte como hacia la sierra meridional del Perú. Torero propone en efecto que, durante el Período Intermedio Tardío $(\approx 1000-1450)$, el poderío de Pachacámac — considerado por él como quechuahablante- habría suscitado la difusión del quechua yunga hacia la sierra norte del Perú, en particular la zona de Cajamarca, y hacia la costa sur, en particular el valle de Chincha. Posteriormente, la intensa actividad comercial terrestre y marítima de los mercaderes chinchanos habría propagado la lengua hacia Ecuador, por un lado, y hacia Ayacucho y Cuzco, por otro (Torero, 1974: 9698; 1984: 371; 2002: 89). En esta última zona, el quechua se habría transformado bajo la influencia de un sustrato aimara para dar lugar a lo que conocemos hoy como el dialecto cuzqueño.

Siempre según Torero, la difusión y el prestigio de la variedad costeña habrían convencido a los incas de adoptarla como «idioma oficial» en vez de su propio dialecto, el quechua cuzqueño (1974: 132-133). En efecto, la lengua vehicular del imperio inca, tal como se observa en la documentación de las primeras décadas después de la conquista española, presenta rasgos que la distinguen 
claramente del quechua del Cuzco tal como aparece en documentos posteriores y hasta hoy. Lo que caracteriza al quechua de los documentos primitivos con respecto a la variedad cuzqueña moderna es la existencia de los alófonos sonoros $b, d, g$, c y g gara los fonemas oclusivos y africados /p/, /t/, /k/, /q/ y /č/ después de la nasal $/ \mathrm{n} /$. Dicho de otra forma, la vibración de las cuerdas vocales que constituye la sonoridad de la consonante nasal afectaba, en la antigua lengua vehicular, la pronunciación de la consonante siguiente. Formas como $<$ cumbi $>$, $<$ condisuyo $>$, <yupangue $>$ y $<$ mango $>$ manifestaban esta regla fonológica. De ello A. Torero dedujo que la variedad de quechua usada como lingua franca en el Tahuantinsuyo no era el quechua cuzqueño sino el de la costa central peruana. El «quechua yunga», en efecto, habría tenido dicho rasgo, pues la sonorización de las oclusivas tras nasal se encuentra hoy solamente en los dialectos quechuas de Colombia, Ecuador y del norte del Perú (Cajamarca, Ferreñafe, Chachapoyas y San Martín), los mismos que, según Torero, procedían de la costa.

La tesis de la existencia de un quechua costeño matriz de los dialectos norteños y sureños del quechua y base de la lengua vehicular del imperio inca ha tenido amplia acogida entre los lingüistas. Rodolfo Cerrón-Palomino la encontró muy convincente (1987: 335) y, recientemente, la reformuló con algunas adaptaciones (2010). Analizó la obra de Domingo de Santo Tomás y los textos contenidos en los Coloquios de la verdad, de Pedro de Quiroga, como testimonios de esa variedad (1990; 1991). Gerald Taylor la consideró probable (1994: 19; 2000: 42) y yo la tomé por demostrada (Itier, 2008: 141). Willem Adelaar también admite la existencia de un dialecto quechua costeño (2010: 243) así como el origen marítimo de los dialectos del norte del Perú y de Ecuador (Adelaar, 2010: 246), pero considera que el dialecto ayacuchano, en el que ve la matriz del dialecto cuzqueño, no tiene sus raíces en la costa (Adelaar, 2010: 248).

En el presente artículo, mostraré que esta tesis no resiste un examen detenido de las fuentes históricas, pues no existe ningún indicio documental de que se hablara quechua en la costa central o centro-meridional antes de que los mismos incas lo introdujeran allí. Veremos que los datos filológicos y la información histórica apuntan más bien a que la variedad de quechua que servía de lengua vehicular en el Tahuantinsuyo tuvo su fuente en el dialecto quechua propio de los incas, que llamaré en este ensayo «cuzqueño antiguo». En efecto, el quechua que hablaban los incas no debe confundirse con el quechua cuzqueño tal como está atestiguado desde el último tercio del siglo XVI y tal como se observa en la actualidad. Como se verá, la variedad de quechua que hablaban los incas sufrió importantes transformaciones al ser aprendida por los numerosos grupos foráneos que los incas habían instalado en el Cuzco y sus alrededores, y que parecen haber constituido la mayoría de la población en las zonas económicamente estratégicas de la región. Después de la conquista española, que significó para los incas una drástica disminución demográfica y la pérdida de su preeminencia política y económica, estos grupos estuvieron en condiciones de imponer varios de sus hábitos lingüísticos en el quechua regional. 


\section{PROBLEMAS DE PLAUSIBILIDAD HISTÓRICA EN LA TESIS DEL QUECHUA COSTEÑO}

El esquema propuesto por A. Torero y hoy admitido por varios lingüistas me parece plantear importantes problemas de plausibilidad histórica. En primer lugar, implica que el factor principal de la difusión del quechua hacia el norte y el sur fueron contactos interculturales efectuados sin el soporte de migraciones ni de la acción de un Estado. En la historia de las sociedades antiguas, no conozco ejemplos de propagación de un idioma comercial — fuera de su uso circunstancial como lingua franca - sin una acción colonizadora duradera o sin que sus hablantes encarnaran un modelo de civilización al que los otros grupos encuentren ventajoso convertirse. Entre las lenguas que se difundieron mediante el comercio, la fortuna del swahili — una lengua bantú fuertemente influenciada por el árabea lo largo de las costas del África oriental se debe a la presencia de una serie de ciudades costeras fundadas por migrantes venidos del Golfo Pérsico. Asimismo, la difusión de la lengua malaya por el archipiélago malayo, a partir del sureste de Sumatra, se debió a la colonización comercial malaya y, secundariamente, a que el Islam se propagó a través de este idioma. Hasta donde sepamos, no se dio ningún fenómeno parecido en los Andes durante el Período Intermedio Tardío, pues no hubo fijación de colonos chinchanos en Ecuador, Ayacucho o Cuzco, ni existen huellas de una influencia cultural costeña en la sierra durante esa época (Heggarty \& Beresford-Jones, 2010: 46). Antes bien, los primeros observadores españoles de la realidad andina notaron el desprecio que los «yungas» inspiraban a los habitantes de la sierra1. En los Andes, como en otras partes del mundo, suelen ser los comerciantes caravaneros quienes aprenden las lenguas locales, pues necesitan pedir la hospitalidad de los habitantes de los lugares que recorren y convencerlos de adquirir sus productos 2 .

Pero son los progresos realizados por la arqueología de la región metropolitana del Tahuantinsuyo a lo largo de la década pasada los que plantean su mayor dificultad histórica a la tesis de una difusión del quechua desde la costa hacia el Cuzco. Sabemos hoy que la expansión imperial inca es el fruto de un largo proceso, iniciado en el siglo $\mathrm{XI}$, de desarrollo de un Estado regional acompañado de un incremento sustancial de la base económica local y de un importante crecimiento

1 Véase, por ejemplo, Pedro Sancho según el cual «Ningún señor de los que han gobernado estas provincias ha hecho nunca caso de la gente de la costa, por ser ruin y pobre como se ha dicho» (1962 [1534]: 193). Por eso, los soldados del Inca trataron de «yungas» a los españoles cuando estos se adentraron por primera vez en las tierras altas: «se juntaron en escuadrones viniendo contra ellos [ = contra los españoles] diciéndoles, INGRES [sic por YUNGAS], el cual nombre tienen ellos por muy afrentoso, siendo esta una gente despreciable que vive en las tierras calientes de la costa del mar, y por ser aquella provincia region fria é ir los Españoles vestidos y cubiertas sus carnes.» (Sancho, 1962 [1534]: 46).

2 Hasta hace una generación, casi todos los hombres del pueblo quechuahablante de Amarete, situado en una quebrada del norte del departamento de La Paz, hablaban el aimara porque transitaban cada año por la zona aimara del norte del altiplano peruano donde vendían o trocaban pan, naranjas y madera de lluqina para fabricar herramientas (Jinés Cornejo Endara, comunicación personal). 
demográfico (Bauer \& Covey, 2002; Bauer, 2004; Covey, 2006). La arqueología nos muestra que, apenas abandonada la colonia huari de Pikillaqta, hacia 1000 d. C., los habitantes del valle del Cuzco empezaron a integrar en una misma formación social a los distintos grupos étnicos de los alrededores. Podemos pensar que este proceso de integración regional implicó el uso de una lengua común. Sabemos que esta no fue el idioma particular de los incas — pues, en el momento de la conquista española, este solo era hablado por ellos-, por lo que no puede haber sido sino el quechua. Pero resulta altamente inverosímil que esta lengua haya sido introducida en la región durante esa época y que los incas renunciaran a su lengua para adoptar la de un pueblo, Chincha, bajo cuya dominación nunca habían estado y que se encontraba muy lejos de su territorio. La hipótesis de una mediación chanca en la transmisión del quechua desde Chincha hacia el Cuzco, sugerida por Torero (1974: 97-98) y retomada por R. Cerrón-Palomino (2010), tampoco encuentra asidero en las investigaciones arqueológicas recientemente llevadas a cabo en la zona de Andahuaylas (Bauer et al., 2010). Estas muestran más bien que los chancas no tuvieron el poderío que la historiografía oficial inca les atribuyó. Los cuzqueños parecen haber sobredimensionado la amenaza que representaban los chancas para legitimar su agresión contra ellos y el inicio de su ciclo de conquistas hacia el oeste del Cuzco. Estos hechos sugieren que la implantación del quechua en la región del Cuzco se remonta a una época anterior a 1000 d. C. De hecho, la arqueología ha empezado a develar las continuidades culturales que unen a los incas de inicios del Período Intermedio Tardío con los colonos huaris establecidos desde la época anterior en la región (Mc Ewan et al., 2002). Cuando Torero formuló su hipótesis estos eran aspectos ignorados e insospechados de la historia del Cuzco. En los últimos veinte años, las investigaciones arqueológicas sobre los incas durante las épocas pre-imperial e imperial han realizado enormes progresos que nos obligan a revisar las hipótesis formuladas hasta ahora acerca de la difusión del quechua hacia esa región. La arqueología sin duda aportará pronto nuevos conocimientos a los cuales la lingüística histórica deberá mantenerse atenta para afinar o rectificar sus hipótesis.

\section{CRÍTICA HISTÓRICA DE LA TESIS DEL QUECHUA COSTEÑO}

La idea del origen costeño del quechua o de un grupo de dialectos quechuas se remonta a un artículo publicado en 1911 por el sacerdote e historiador peruano Manuel González de la Rosa quien, observando que el quechua descrito por Domingo de Santo Tomás en 1560, así como la toponimia quechua costeña (Lima, Limatambo), presentaban aparentemente el fonema /// donde el quechua cuzqueño tenía /r/, concluyó que se había hablado en la costa una variedad de quechua distinta al cuzqueño y que, por lo tanto, dado el poco tiempo que había durado la dominación inca sobre las regiones marítimas, esa lengua no podía haber sido introducida allí por los cuzqueños sino que su presencia en el litoral debía ser anterior al Tahuantinsuyo. Según González de la Rosa, la costa constituía incluso el territorio original del quechua (1911: 1208). 
Este artículo parece estar en el origen de la hipótesis formulada cuatro décadas después por el historiador Raúl Porras Barrenechea en su prólogo a su edición del Lexicón de Domingo de Santo Tomás. Porras observó también las diferencias existentes entre el quechua descrito por el dominico y el dialecto cuzqueño, y pensó que el Lexicón registraba un dialecto quechua costeño, pues Santo Tomás, aparte del Cuzco, el Collao, Huaylas y Conchucos, había permanecido largamente en el litoral. Como González de la Rosa, Porras supuso que la presencia del quechua en las regiones marítimas era anterior al Tahuantinsuyo y que esta lengua se había propagado hacia el sur del Perú desde la costa centro-meridional (in: Santo Tomás, 1951a: XV).

Las líneas que Porras dedicó a este tema tuvieron un enorme impacto, pues tanto Gary Parker como Alfredo Torero asumieron la existencia de un dialecto quechua costeño extinto y cuya formación y presencia en el litoral era anterior al Tahuantinsuyo (Parker, 1963: 249; Torero, 1964: 475). Los argumentos toponímicos de González de la Rosa, por más escuetos que fueran, convencieron a varios lingüistas de que ese quechua costeño presentaba un cambio ${ }^{*} r>1$ en posición inicial de palabra (Cerrón-Palomino, 1990: 356-357; Taylor, 2000: 37). Único en manifestarse en contra de la opinión general, Bruce Mannheim señaló que, en el prólogo de su Lexicón, el dominico afirmaba describir la lengua «general y entendida por toda la tierra, y mas vsada de los señores, y gente principal, y de muy gran parte de los demas Indios.» (1991: 260, nota 13). El hecho de que Santo Tomás no describió un dialecto geográficamente localizado sino una lingua franca susceptible de múltiples inflexiones locales se manifestaba en el carácter profundamente pluridialectal de su Lexicón (Mannheim, 1991). Finalmente, Mannheim señalaba que así lo percibió también Huaman Poma para quien el diccionario de Domingo de Santo Tomás registraba «la lengua del Cuzco chinchaysuyo quichiua todo rrebuelto» (Guaman Poma, 1936 [1615]: 1079). Curiosamente, pese a estas cruciales observaciones de B. Mannheim, la tesis del quechua costeño mantuvo su credibilidad.

Alfredo Torero trató de explicar la introducción del quechua en el actual Ecuador por una penetración comercial chinchana durante los siglos que precedieron el imperio inca (1974: 79-98; 1984: 371-372). Se apoyó en un documento redactado entre 1570 y 1575 , el «Aviso de el modo que havia en el gobierno de los indios en tiempo del inga», publicado y analizado por María Rostworowski (1977 [1970]). Según este documento, los mercaderes de Chincha «con sus compras y ventas iban desde Chincha al Cuzco por todo el Collao, y otros iban a Quito y a Puerto Viejo, de donde traían mucha Chaquira de oro y muchas esmeraldas ricas y las vendian a los caciques de Ica» (Rostworowski, 1977 [1970]: 138). M. Rosworowski y A. Torero dedujeron de esta frase que los mercaderes de Chincha practicaban antes de la época inca un comercio marítimo intenso a lo largo de las costas de lo que hoy es el Perú y Ecuador. Esta tesis ha recibido las críticas de varios autores, tanto historiadores como arqueólogos. Roswith Hartmann (1979) la ha sometido a un examen detallado de las fuentes históricas ecuatorianas y ha concluido que estas no respaldan la presencia preincaica del quechua en Ecuador. Apuntan más 
bien a que los incas fueron los primeros en introducir este idioma en los Andes septentrionales. En 1993, Anne Marie Hocquenghem observó que Rostworowski y Torero habían interpretado abusivamente el «Aviso» creyendo ver en él la prueba de un comercio marítimo entre Chincha y Ecuador cuando, en realidad, este documento no precisa si los viajes de los chinchanos alcanzaban Puerto Viejo y Quito por la vía marítima o terrestre. Más bien, A. M. Hocquenghem ha mostrado que las evidencias arqueológicas, iconográficas e históricas no respaldan la tesis de un uso comercial de la navegación a lo largo de las costas peruanas. Por añadidura, la corriente de Humboldt hacía excesivamente largos y dificultosos los viajes de norte a sur, por lo menos para embarcaciones del tamaño que se atribuía a los mercaderes chinchanos ${ }^{3}$. A todas luces, estos debieron viajar hacia Quito como lo hacían hacia Cuzco y el Collao, es decir por tierra y con llamas. Cieza, en efecto, señala que los camélidos abundaban en el valle de Chincha (2005 [1553]: 203, cap. LXXIV). Aunque Gabriela Ramos ha mostrado, en base a informaciones archivísticas del siglo XVI, la existencia de un cabotaje indígena entre la costa central y la costa norte e, incluso, Panamá (2011: 24-26), resulta poco probable que esta navegación costera pudiera ser lo suficientemente masiva como para suscitar la difusión de un idioma desde Chincha hasta los Andes del norte. Quedaría la posibilidad de una expansión terrestre de la lengua de los chinchanos. Pero esta hipótesis tropezaría a su vez con la dificultad de entender por qué esa lengua se habría arraigado en los puntos más distantes de su recorrido - a unos $1500 \mathrm{~km}$ a vuelo de pájaro- y no en los espacios intermedios, todo eso sin ninguna implantación permanente chinchana en el norte del Perú y Ecuador.

Sea lo que fuere, la tesis de un comercio preincaico entre Chincha y Ecuador encuentra su refutación a mi parecer definitiva en una observación formulada por Daniel Sandweiss (1992: 10). Según este arqueólogo, los numerosos objetos no chinchanos que se han encontrado en Chincha datan en su totalidad de la época inca, de modo que el comercio chinchano a larga distancia solo adquirió una dimensión significativa bajo la dominación cuzqueña. D. Sandweiss formula la hipótesis según la cual el rol de los chinchanos en los intercambios económicos entre los Andes del norte y del sur fue la consecuencia de la conquista del imperio chimú por los incas. En la época anterior, la presencia de este Estado entre la costa central y Ecuador, así como los conflictos que oponían los chinchanos a sus vecinos inmediatos, constituían obstáculos mayores a un comercio a larga distancia entre Chincha y Ecuador o Cuzco. La situación descrita por el «Aviso» corresponde en realidad a la época inca y no al Período Intermedio Tardío.

Pero lo que definitivamente descalifica la tesis del quechua costeño es que la documentación histórica no respalda de ninguna manera la idea según la cual se habría hablado quechua en la costa. Porras afirmaba que el quechua, «originario de la costa», «según algunos cronistas y conquistadores [...] se habría infiltrado antes de la época incaica a las regiones andinas del Sur» (in Santo Tomás, 1951a: XV). En realidad, los cronistas y conquistadores a los cuales aludía Porras se 
reducen a uno solo: el mercedario fray Martín de Murúa, que escribió hacia 1590 una crónica novelesca de la historia incaica. Examinemos lo que dice este autor:

A este Ynga Huayna Capac, se atribuye haber mandado en toda la tierra se hablase la lengua de Chinchaysuyo, que agora comúnmente se dice la Quichua General, o del Cuzco, por haber sido su madre Yunga, natural de Chincha, aunque lo más cierto es haber sido su madre Mama Ocllo, mujer de Tupa Inga Yupanqui su padre, y esta orden de que la lengua de Chinchay suyo se hablase generalmente haber sido por tener él una mujer muy querida, natural de Chincha. (Murúa, 1987: 136, libro I, cap. XXXVII)

A. Torero (1974: 151-152) y R. Cerrón-Palomino (1987: 327-328) han visto en estas frases una prueba de la existencia de un dialecto quechua costeño y de su oficialización por los últimos incas. Sin embargo, Murúa no dice que se hablaba quechua en Chincha ni que Huayna Cápac tomó de Chincha la lengua general de su imperio. Dice más bien que el Inca convirtió el quechua chinchaysuyo en lengua «general» porque una mujer muy querida suya o su madre, por ser chinchana, hablaba esta variedad. Esta mujer bien pudo hablar «la lengua de Chinchaysuyo» como lengua segunda y franca, y no como lengua propia, pues el valle de Chincha se encontraba cerca de regiones serranas de habla «chinchaysuya». Estas frases de Murúa podrían leerse entonces como un testimonio del uso de un dialecto quechua serrano local en la comunicación entre los yungas y los habitantes de las tierras altas.

Pero el principal objetivo del mercedario al referir esta anécdota era encontrar una respuesta al siguiente problema: ipor qué la dominación inca suscitó la propagación de formas de quechua distintas del cuzqueño, recibiendo incluso estas la denominación de «lengua del Cuzco»? Murúa explica esta incongruencia por una política idiomática laxista de parte de Huayna Cápac: en vez de velar por la difusión de su propio quechua, «el más puro y acendrado del reino», el Inca dio preferencia al rudo dialecto del Chinchaysuyo, el que manejaba su madre o su favorita. Pierre Duviols (1962) y John Rowe (2003a: 127-134) han mostrado cuán poco confiables son las informaciones proporcionadas por el mercedario, plagiario y falsario de desbordante imaginación ${ }^{4}$. Adviértase además que los hechos aquí referidos por Murúa son totalmente inverosímiles desde un punto de vista histórico, pero muy acordes con el tono ligero y galante de la Historia general del Perú cuyo autor se complace en evocar la virtud de los príncipes y de las damas, y sus debilidades amorosas. Tal es el único sustento documental de la tesis de la «oficialización» por los incas de un supuesto quechua costeño.

Como prueba de la existencia de un dialecto quechua propio de la costa o de Chincha, R. Cerrón-Palomino (1990: 357) y A. Torero (2002: 132-133) han traído a colación la «Relación y declaración del modo que este valle de Chincha y sus

4 Rowe escribe por ejemplo: «... no faltan casos [...] en que autores que escriben sobre historia han sacrificado la veracidad en busca de los que ellos consideran la calidad literaria. El escritor mercedario Fray Martín de Murúa nos presenta un caso exagerado de un autor que busca el éxito literario y llega a la mentira por medio del plagio.» (2003a: 127) 
comarcanos se gobernaron antes que hobiese ingas y despues que los hobo hasta que los cristianos entraron en esta tierra» firmada en febrero de 1558 por el dominico fray Cristóbal de Castro, vicario del convento de Santo Tomás, en Chincha, y el corregidor Diego de Ortega Morejón. Según R. Cerrón-Palomino y A. Torero, este documento contendría muestras de un fenómeno de lateralización de $* / r /$ en dicho dialecto. En realidad, los elementos de léxico quechua que figuran en dicha relación - concretamente la denominación de las doce edades en que se empadronaba la población_ - no fueron recogidos en el valle de Chincha sino que Castro y Ortega los copiaron literalmente de la «Relación del origen é gobierno que los Ingas tuvieron y del que había antes que ellos señoreasen á los indios deste reino...» redactada un año antes por el visitador Damián de la Bandera en Huamanga, como ya lo había notado Guillermo Lohmann Villena (1966).

La única información que contiene la «Relación» de Castro y Ortega acerca de la situación lingüística de la costa sur-central es la que ofrecen los nombres de los curacas de los valles de Chincha, Ica y Lunaguaná: Guabiarucana, Aranbilca y Caciarucana, respectivamente. Estos nombres parecen pertenecer a la lengua aimara antes que a la quechua. El primero puede interpretarse como waywa ruk'ana cuyo significado fue tal vez 'dedo del viento'; el segundo como < aran> willka 'señor (¿de la parte alta?)'; y el tercero como qhaqya ruk'ana 'dedo del trueno'. Esto no significa que la lengua particular de los chinchanos haya sido el aimara sino, tal vez, que las élites chinchanas adoptaron la antroponimia de un pueblo de la sierra aledaña bajo cuya tutela o influencia se encontraron en algún momento de su historia, como lo observamos en el caso de otros grupos andinos que adoptaron parcial o totalmente una antroponimia quechua al mismo tiempo que conservaban su lengua particular.

Desde González de la Rosa, los partidarios de la tesis del quechua costeño mencionan, como prueba de una presencia antigua del quechua en la costa central y sur-central, la existencia de una toponimia perteneciente a este idioma (Lima, Limatambo, Lurín, etc.). En realidad, los topónimos claramente atribuibles al quechua en ese sector de la costa no son numerosos, mucho menos en todo caso que en regiones donde esta lengua recién se difundió en la época inca, como la sierra ecuatoriana. Esta toponimia muy bien puede explicarse por la presencia administrativa y cultural inca, que fue particularmente importante entre Lima e Ica, como lo muestra abundantemente la arqueología (por ej. Ángeles Falcón, 2010: 163-164). A fines del siglo XVI, el mismo Martín de Murúa fue testigo de la presencia del quechua en la costa y la atribuyó a la política lingüística inca (contradiciendo la interpretación que se ha querido dar al pasaje suyo citado más arriba):

El lenguaje que en estos Ilanos se habla, propio y nativo, es muy diverso que el de la sierra, y dificultosísimo de pronunciar por otros que ellos, por ser la pronunciación gutural, aunque por la mayor parte hablan y entienden la lengua quichua y general, que el Ynga les dio. (1987: 464, libro III, cap. II) Todas las informaciones proporcionadas por los cronistas coinciden en que no se hablaba quechua en la costa central antes de la dominación inca. En 1649, Diego de Molina señala que la «lengua materna» del valle de Lima no era el quechua 
sino otro idioma, aunque los indígenas también conocían la lengua general (in Romero, 1928: 65). Asimismo, en 1653, Bernabé Cobo nos informa que se hablaban dos lenguas no quechuas en esa zona:

Antes de la venida de los españoles a esta tierra estaba este valle [del Rímac] y comarca muy poblado de indios, como lo muestran las ruinas de sus pueblos; eran dos las naciones que lo habitaban, con lenguas distintas, las cuales aún conservan los pocos que quedan de ambas. Los naturales de Caraguayllo y sus términos eran de la una nación, cuya lengua corre desde allí adelante por el corregimiento de Chancay y banda del septentrión; y desde el mismo pueblo de Caraguayllo hasta el de Pachacamac habitaba la otra nación (Cobo, 1956 [1653]: 301, t. II, cap. VII).

Sabemos que la población de la costa central colapsó casi completamente después de la Conquista (Cook, 2010: 201-222). Los ayllus yuncas de la provincia de Huarochirí, por ejemplo, sufrieron una dramática baja demográfica (Salomon \& Grosboll, 2011: 54). La casi totalidad de la población indígena de la zona de Lima en la época colonial eran migrantes de diversos lugares de la sierra $-y$ no exclusivamente del arzobispado metropolitano- (Ramos, 2010: 170-172). La lengua común que adoptó esta población instalada en la capital parece haber sido la lengua general y no un dialecto QI del tipo de los que se hablaban en la sierra cercana, pues, en la primera mitad del siglo XVII, Francisco de Ávila predicó en ella sus sermones.

La lengua general también estaba presente fuera de la capital. Las visitas que Toribio de Mogrovejo (2006) llevó a cabo en el arzobispado limeño entre 1593 y 1605 muestran que, desde Pativilca hasta por lo menos Lima, los habitantes de la costa entendían la «lengua general», es decir una forma de quechua derivada del cuzqueño, y eran «doctrinados» en ella, aunque sabemos por otras fuentes, y también por la antroponimia que aparece en diversos documentos, que todos estos valles tenían sus «lenguas particulares» diferentes del quechua. En el siglo XVII, el conocimiento de la lengua general era obligatorio para todos los curas que pretendían a una doctrina tanto en la sierra como en la costa del arzobispado de Lima $^{5}$. Cobo discurre acerca de la pronunciación de esta última lengua por los costeños atribuyendo sus peculiaridades a una lengua de sustrato:

... los naturales de esta comarca y todos los demás de los Llanos dicen Limac, y los serranos Rimac [...] La razón de hallarse esta desconformidad entre los serranos y marítimos, es por ser este nombre Rimac propio de la lengua Inga, que es la materna de aquéllos, particularmente de los del Cuzco, la cual hablan los serranos con más propiedad y elegancia, y los de los Llanos la usan algo corrupta, como extraña y peregrina; porque cuando los españoles entraron en esta tierra, habían pasado pocos años que los Incas, reyes del Cuzco, habían sojuzgado estas provincias marítimas e introducido su lengua en los habitadores de ellas, de donde vino el no

5 Como se observa en los expedientes de la sección Concursos del Archivo Arzobispal de Lima. 
hablarla con la perfección de los serranos. (Cobo, 1956 [1653]: 292-293, t. II, cap. IV) ${ }^{6}$

Esta es la explicación del fenómeno de lateralización de */r/ en el quechua hablado por los habitantes de la costa central. Se trataba de un hábito heredado de su lengua propia y transferido al quechua que habían aprendido reciente e imperfectamente.

Finalmente, la tesis según la cual una variedad de quechua ya funcionaba como lingua franca en los Andes antes de la dominación inca tropieza con las fuentes históricas que insisten unánimemente en el rol de los incas como propagadores exclusivos de la «lengua del Cuzco». Según el visitador eclesiástico Cristóbal de Albornoz (ca 1580), que recogió informaciones originales en las regiones que hoy pertenecen a los departamentos de Huancavelica, Ayacucho, Apurímac y Cuzco, no existió una lingua franca de amplia difusión en el Perú en la época inmediatamente anterior al imperio inca:

Ase de considerar que, antes que los Ingas, señores que conquistaron desde la provincia del Cuzco hasta Chile y hasta Pasto, en los naturales de toda esta tierra nunca ovo gobierno ni lengua general sino por provincias a las quales governavan por subcesión los indios de más valor (Albornoz, 1967: 17).

\section{IDENTIDAD DE LA LENGUA VEHICULAR DEL IMPERIO INCA Y DEL QUECHUA CUZQUEÑO ANTIGUO}

Desde un punto de vista filológico, la tesis según la cual los incas habían «oficializado» la variedad costeña del quechua en vez de la suya propia se apoya en la observación de dos diferencias fónicas entre la lengua vehicular y lo que hoy conocemos como quechua cuzqueño. La primera consiste en la pronunciación de las oclusivas tras nasal, que la lengua común sonorizaba mientras que las variedades actuales del quechua meridional no lo hacen. La segunda diferencia atañe a la pronunciación de una de las dos sibilantes del quechua. Como lo vamos a ver, la lengua general del Tahuantinsuyo oponía una sibilante alveolar o alveodental $/ \mathrm{s} /$ a una sibilante palatal /̌s/, mientras que el quechua cuzqueño, por lo menos tal como está atestiguado a partir del último tercio del siglo XVI, parece haber opuesto la alveolar a una sibilante apical / $/ \mathbf{s} /$ tal vez ligeramente retrofleja como en el actual quechua huanca (Landerman, 1982; Mannheim, 1991: 153-176; Cerrón-Palomino, 1989: 28-30). Muchos préstamos tempranos del quechua en español ostentan estos rasgos: tambo $(<$ tanbu), Ande $(<$ andi), pongo $(<$ pungu), ojota $(<$ ušuta), etc.

Examinemos algunas evidencias de lo anterior. Los nombres de los principales pueblos y provincias del Perú fueron los primeros elementos de la lengua quechua

6 Huaman Poma registra también esta pronunciación yunga del quechua, por ejemplo en estos dos gentilicios: < Solco yunga $>$ y < Lata yunga $>$ (1936: 1073). 
en ser registrados por la escritura. Casi todos los que contienen una consonante oclusiva tras /n/ la sonorizan. Lo observamos en el nombre de la ciudad inca de Bombón que aparece ya en un documento de 1533 (Pizarro, 1968). Las referencias a la toponimia se vuelven más numerosas a partir de 1534. Una carta escrita por Diego de Almagro a Carlos Quinto en ese año menciona $<$ Condesuyo $>$ o $<$ Condisuyo $>$, es decir [kundi suyu] (Porras, 1959: 108). El mismo año, la misma forma aparece en la crónica de Pedro Sancho (1962: 85-86). Una carta de Pizarro al cabildo de Panamá menciona <Vilcaconga >, es decir [willka kunga] (Porras, 1959: 115) y una carta del ayuntamiento de Jauja al emperador vuelve a aludir al centro administrativo inca de <Pombo >, es decir [punbu] (Porras, 1959: 125). Miguel de Estete (1968: 381), Pedro Sancho (1962: 29) y Francisco de Jerez (Xerez, 1891: 137) registran la misma forma. Siempre en 1534, Pedro Sancho transcribe los nombres de $<$ Andabailla $>=$ [anda waylla] (Sancho, 1962: 48, 50), $<$ Curamba $>i=$ [kuranba]? (Sancho, 1962: 50) y $<$ Caxatambo $>=[$ kaša tanbu] Sancho, 1962: 28), siendo este último nombre también consignado por Francisco de Xerez (1891: 136) junto con <Tumepomba $>=$ [tumi panba] (Xerez, 1891: 69, 104), Taurichumbi = [tawri chunbi] (Xerez, 1891: 133) y Guaranga = [waranca] (Xerez, 1891: 135).

La sonorización de /q/ y / k/ tras /n/ se observa también en la antroponimia inca que recién empieza a abundar en los documentos a partir de fines de la década de 1530, por ejemplo en <Mango ynga Yupangue > (en una carta de 1539 in: Porras, 1959: 337) o <Tey-Yupangui > —probablemente por Maita Yupangui [mayta yupangi]— (Anónimo, 1968 [1539]: 545). En la mayoría de los casos, se trata de nombres de miembros de la élite inca que vivían en varias zonas del imperio, incluido el Cuzco. Uno de los primeros nombres comunes en aparecer en la documentación es el término genérico que designaba a los costeños o <yungas $>$ (Silva y Guzmán, 1968 [1538]: 105), que ofrece otro caso de sonorización. Asimismo, un testigo de los acontecimientos de Cajamarca, Diego de Trujillo, recuerda que Atahualpa después de arrojar el libro exclamó:

«Ea ea que no se escape ninguno y los indios dijeron $\mathrm{Ho}$, inga, que quiere decir, hágase así y el alarido puso gran temor.» (1968 [1571]: 24).

Las primeras transcripciones de nombres y términos quechuas atestiguan también el contraste de sibilantes $/ \mathrm{s} /$ - / $/ \check{S} /$. Aun en toponimias y antroponimias de la región del Cuzco: <xaquixaguana> ([šakša wana]) (Estete, 1968 [hacia 1535]: 389), <Guaxcar> ([waškar] o [waškhar]) (Estete, 1968 [hacia 1535]: 378), <Cochacaxa> ((quča kaša]), un tambo situado entre Curamba y Abancay (Anónimo, 1968 [1539]: 574). El primer libro de cabildo del Cuzco, redactado en 1534, atestigua tanto el fenómeno de sonorización como la existencia de una sibilante $/ \check{s} /:<$ Tupa Inga $>$ [t'thpa inga] —otro nombre de Manco—, Xaxixaguana ([šakša wana]), Caxana (un solar en la plaza), Guaxacar (Rivera Serna, 1965).

En la década de 1550, las crónicas de Pedro Cieza de León y Juan de Betanzos nos proporcionan los primeros registros de frases en la «lengua del Cuzco». De Cieza solo citaré un ejemplo: 
$<$ Ancha hatun apo yndechori>

[anča hatun apu, indi churi]

« iO muy gran señor, hijo del Sol! » (1996: 15).

Juan de Betanzos, cuyos interlocutores fueron en su gran mayoría incas del Cuzco, registró casi exclusivamente formas que presentaban las características mencionadas: <Cochabamba $>=$ [qucha panba] o [qucha banba] —nombre de un puente sobre el río Apurímac-, <yndi $>$ ([indi] 'sol'), < lnga Yupangue $>$, $<$ canga $>$ ([kanca] 'será'), <xacxahuaman urco $>$ ([šaqša waman urqu] 'cerro de Sacsayhuamán') (Betanzos, 1987: 170). De los varios textos cortos que contiene su Suma y narración citaré solo un ejemplo:

$<$ aco çapa Ynga aucayquita atixu llactaioc tiangui cuna(n) punchaupi> [haku sapa inga, awqaykita atišun, llaqtayuq tiyangi kunan p'unčawpi] «vamos sólo rey y venceremos a tus enemigos que hoy en este día ternas contigo prisioneros» (traducción original) (Betanzos, 1987: 32-33)

Los ejemplos abundan hasta la década de 1560, particularmente en la onomástica cuzqueña, y muestran claramente que el quechua que hablaban los incas tenía una sibilante palatal /̌s/ y sonorizaba las oclusivas tras nasal. Sin embargo, hay que señalar que, aunque las formas con sonorización predominan ampliamente en la documentación temprana, aparecen esporádicamente formas que no la tienen, por ejemplo <inca $>$ e <ynca $>$ en una carta escrita en 1539 por Valverde al Emperador (Porras, 1959: 323) o <manco $>$ en otra carta del mismo año (Porras, 1959: 352). Esta alternancia de formas con y sin sonorización podría explicarse por el hecho de que los españoles frecuentaban indígenas que tenían diversas pronunciaciones. Otra explicación, que me parece más plausible, sería que el cambio [sorda $\rightarrow$ sonora / tras n] no estaba consumado en el quechua inca y que se daba todavía en ese dialecto cierta variación libre entre formas sordas y sonoras. Esto se reflejaría en el hecho de que la sonorización de las oclusivas tras / $\mathrm{n} /$ tampoco es un cambio consumado en la mayoría de los dialectos ecuatorianos (Landerman, 1982: 241) cuya matriz es, como lo mostraré en un trabajo posterior, la variedad hablada por los incas.

\section{LA FORMACIÓN DEL QUECHUA CUZQUEÑO MODERNO}

La tesis del origen costeño de la lengua vehicular del Tahuantinsuyo procede de un supuesto aparentemente asumido como una evidencia por nuestros colegas: el quechua cuzqueño, tal como lo conocemos hoy, sería la continuación simple y directa del quechua que hablaban los incas. Como lo vamos a ver en este acápite, la documentación histórica permite pensar que, en las décadas que siguieron la conquista española, la variedad de quechua que hablaban los incas quedó sepultada, en la misma región del Cuzco, por un intenso proceso de homogeneización lingüística.

Como lo observa Gabriela Ramos, la historiografía ha prestado poca atención al hecho de que los incas habían instalado una enorme cantidad de colonos foráneos 
(mitma) en el valle del Cuzco y en otras quebradas aledañas (Ramos, 2011: 27). Los testamentos producidos por indígenas en la ciudad del Cuzco en la segunda mitad del siglo XVI y colectados por esta autora muestran que un gran número de cañaris, chachapoyas, yauyos, huancas y huanuqueños vivían en la ciudad y sus alrededores (Ramos, 2011). Aunque algunos de estos migrantes llegaron acompañando a los españoles, en su mayoría fueron instalados en la región por los incas. En la primera parte de su Crónica del Perú, Cieza de León menciona repetidas veces esta realidad:

Lo más de la ciudad [del Cuzco] fue poblada de Mitimaes (2005: 240)

Y como esta ciudad [Cuzco] estuuisse llena de naciones extranjeras y tan peregrinas, pues auía Indios de Chile, Pasto, Cañares, Chachapoyas, Guancas, Collas: y de los más linages que ay en las prouincias ya dichas. [las cursivas son mías] (2005: 241)

Y mandó [Topa Ynga Yupangue] que fuesen ellos [los Cañares] al Cuzco a estar en la misma çibdad más de quinze mill hombres con sus mujeres y el señor prençipal dellos para los tener por rehenes; y fue hecho como lo mandó. [las cursivas son mías] (1996: 163)

Y ase de entender que la çibdad del Cuzco también estava llena de gentes extranjeras, todo de industria, porque aviendo muchos linajes de hombres, no se conformasen para levantamiento ni otra cosa que fuese de servicio de rey; y déstos oy día están en el Cuzco, Chachapoyas y Cañares y de otras partes, de los que han quedado de los que allí se pusieron. [las cursivas son mías] (1996: 66-67)

Betanzos también insistió en la presencia de numerosísimos foráneos en el Cuzco y sus alrededores:

[Yamque Yupangue] mandó que de cada valle [de la costa] los caciques de los tales valles le diesen cada uno dellos un principal con ciertos indios los cuales sacasen de sus tierras todas las semillas ansi de frutas como de las demás comidas y proveimientos y ansi sacó y trujo consigo a la ciudad del Cuzco estos tales Yngas en la manera ya dicha (1987: 123)

[Yamque Yupangue] mandó a los naturales de Quito y a los demás comarcanos y provincias de entorno dél y de los guancabilcas y cañares y yungas les diesen quince mil indios los cuales ansi saliesen a él por el camino por do iba y que fuesen mancebos casados con sus mujeres y semillas de sus tierras para los que querían poner por mitimaes en los valles y redondez del Cuzco [las cursivas son mías] (1987: 128)

Y allí [en el valle del Vilcanota] hizo Guayna Capac que se edificasen muchos pueblos pequeños de a veinte y a treinta y cincuenta indios en los cuales pueblos puso muchos indios mitimaes de todas las naciones y provincias de la tierra [las cursivas son mías] (1987: 187)

No solo los valles del Cuzco y del bajo Vilcanota fueron repoblados por colonos extranjeros sino también el de Abancay (Espinosa Soriano, 1973) y, probablemente, el de Jaquijaguana, es decir, la zona situada entre Limatambo 
y Puquiura7. En la época inca, la región del Cuzco debió presentarse como un verdadero microcosmos lingüístico en el que podían oírse todos los idiomas del Tahuantinsuyo, incluidas varias variedades del quechua. En su juventud, Garcilaso fue testigo de esta realidad. Al describir la fiesta del Corpus Christi, a la que asistió, observa:

Los indios de cada repartimiento pasaban con sus andas, con toda su parentela y acompañamiento, cantando cada provincia [= cada nación] en su propria lengua particular materna, y no en la general de la Corte, por diferenciarse las unas naciones de las otras. (Garcilaso, 1959 [1617]: 787, libro VIII, cap. I)

Debo a la gentileza de Gabriela Ramos el haber podido consultar los testamentos inéditos de indígenas de los siglos XVI y XVII transcritos por ella en los archivos cuzqueños. Estos documentos confirman las observaciones de Cieza y Betanzos: hasta fines del siglo XVI, una importante proporción de estos testamentos fue producida por personas que llegaron al Cuzco antes de la Conquista o con los conquistadores, o de hijos de personas oriundas de los más diversos lugares del Tahuantinsuyo: Cañar, Cayambi, Puruay, Quito, Huamachuco, Huánuco, Tarma, Jauja, Yauyos, Chachapoyas, Huamanga, Andahuaylas, Quichuas, Chumbivilcas, el Collao, Canas, Condesuyos, Yanaguaras, Arequipa, Acarí, San Gabán, así como muchos valles de la costa. Muchas personas aparecen mencionadas en estos testamentos que precisan el origen de parte de ellas. En otros casos, la antroponimia permite determinar claramente si son nativas de la región del Cuzco o si son oriundas de otras zonas del Tahuantinsuyo. Descartando numerosos casos inciertos, he podido determinar de esta manera el origen de noventa personas que aparecen en los testamentos producidos entre 1559, fecha del primero de ellos, y 1600, cuando mueren las últimas personas en haber llegado al Cuzco antes de la conquista española. De ellas, 46 son de origen local y 44 de origen foráneo, aunque en realidad la antroponimia sugiere que deberíamos incluir entre los migrantes a un número mucho mayor de personas. Si bien los testamentos que han llegado hasta nosotros tal vez no sean representativos de la proporción real de los indígenas y los forasteros, estos datos sugieren que por lo menos la mitad, y probablemente mucho más, de la población del Cuzco y las quebradas aledañas procedía de otras regiones del imperio.

Por otra parte, las fuentes muestran que, después de la conquista española, el sector superior del grupo inca generalmente no permaneció en la cúspide de la pirámide de la sociedad indígena local:

este testigo saue y ha visto que los dhos yngas nietos de los yngas señores al presente andan pobres y necesitados e siruiendo e trauaxando como

7 En Zurite, Guarocondo, Anta y Puquiura, «Todos o la mayor parte tienen diferentes lenguas, pero la que hablan es la general» (Fornee, 1965 [1586]: 17). Refiriéndose a los pueblos de Chinchaypuquio, Pantipata, Pivil y Zumaro, el mismo autor dice que: «[en tiempo del inga] se gobernaban estos pueblos por un capitan quel inga ponía, y que estos eran criados del inga traídos de otras partes» (Fornee, 1965 [1586]: 22). 
yndios comunes y no como del linaxe que son a caussa que en tiempo de Challcochima y quisquis mataron a sus padres los quales quedaron niños en muy pequeño. (Rowe, 2003b: 108)

los dhos yngas andan muy pobres y como hatunlunas a caussa de que los españoles tomaron sus tierras. (Rowe, 2003b: 114)

Aunque en su conjunto los incas, o los «Cuzcos» como más a menudo se llamaban a sí mismos, lograron mantener su identidad, cohesión y presencia local, así como cierto poder durante todo el período colonial (por ej. Garret: 2005; Ramos: 2010), la vida indígena regional dejó de organizarse completamente alrededor de ellos. Un cambio social tan profundo no pudo dejar de tener consecuencias lingüísticas. En la región del Cuzco, la conquista española significó la desintegración de un sistema de comunicación articulado «verticalmente» alrededor de un grupo relativamente restringido, los incas, y el advenimiento de un sistema «horizontal» donde estos ya no eran sino un componente minoritario, aunque destacado, de la sociedad local. La ruina que los afectó los integró dentro de nuevas redes sociales en las cuales ya no ocupaban una posición tan central y prominente como antes. Los testamentos transcritos por Gabriela Ramos los muestran interactuando más o menos en igualdad de condiciones con una enorme cantidad de migrantes que se dedicaban al comercio, la artesanía y la agricultura en la ciudad y en los pueblos de la región.

Me parece que este cuadro permite explicar los cambios radicales que sufrió el quechua cuzqueño alrededor de mediados del siglo XVI. Los principales son a mi parecer los siguientes:

1. La regla de sonorización de las oclusivas y la africada tras /n/ dejó de aplicarse bajo la presión de las variedades quechuas más conservadoras originalmente habladas por muchos mitmas y yanaconas (y tal vez también bajo la influencia de otras lenguas «maternas»).

2. Se abandonó la sibilante palatal/š/ en beneficio de la apical//̂s/, aunque pronto las dos sibilantes se fusionarían a su vez en una sola $/ \mathrm{s} / 8$. Se puede conjeturar que este cambio se debe a la influencia de variedades sureñas hoy extintas que, como el quechua huanca, tenían una sibilante apical / $/ \mathbf{s} /$ en lugar de una sibilante palatal.

3. El cambio /s/ > /h/ en posición inicial de palabra, muy avanzado en el quechua hablado por los incas, retrocedió, restituyéndose al quechua cuzqueño una serie de formas más conservadoras, por ej. saqi- 'dejar', que remplazó haqi- o sach'a que remplazó hach'a. Solo la influencia de una variedad en este aspecto más conservadora que el cuzqueño antiguo puede explicar este cambio.

4. Una drástica simplificación morfológica: la obra gramatical y lexicográfica de Diego González Holguín $(1607 ;$ 1608), contemporánea en su elaboración del trabajo del equipo del Tercer Concilio pero cuyas fuentes textuales parecen

8 Los testamentos transcritos por Gabriela Ramos muestran que en la década de 1560 ya predominaba en el Cuzco la norma que oponía /s/ a /s/. 
ser anteriores, describe un sistema morfológico mucho más complejo que el que aparece en los textos conciliares, siendo este último el que se impondrá en el quechua cuzqueño en el transcurso del siglo XVII. A título de ejemplo, González Holguín describe 24 sufijos posverbales de los cuales solo 15 se han mantenido en el quechua cuzqueño moderno.

5. Una regularización del régimen acentual que llevó a una generalización de la acentuación en la penúltima sílaba. En efecto, el sistema acentual complejo del quechua descrito por Domingo de Santo Tomás correspondía probablemente al cuzqueño antiguo, pues encontramos hoy sus huellas en algunos dialectos ecuatorianos.

Los traductores de los textos del tercer concilio mencionan cambios profundos en el léxico del quechua cuzqueño durante el siglo XVI. Explican en efecto que optaron por una forma de quechua común contra «la demasiada curiosidad, con que algunos del Cuzco, y su comarca vsan de vocablos, y modos de dezir tan exquisitos, y obscuros, que salen de los limites del lenguaje, que propriamente se Ilama Quichua, introduziendo vocablos que por ve(n)tura se vsauan antiguamente, y agora nò, o aprouechandose de los que usauan los Ingas, y señores, o tomandolos de otras naciones con quien tratan.» (Tercer Concilio de Lima, 1584: 74r) Los textos conciliares reflejarían la forma de hablar de los nuevos hablantes del quechua cuzqueño, en contraposición con la de los «lncas, y señores». Los jesuitas, que dominaron el tercer concilio limeño, optaron por elaborar un sermo humilis a partir de una variante simple y «vulgar» de la lengua común, rechazando una variedad que hubiera podido ser más prestigiosa pero que consideraban elitista. Es posible que el anti-incaismo toledano, dominante por esos años, contribuyera a esa elección?.

\section{CONCLUSIÓN}

Si la lengua vehicular del Tahuantinsuyo no fue sino la variedad de quechua que hablaban los incas, pueden formularse nuevas preguntas que también deberán ser objeto de investigación. Ya que el quechua no fue llevado al Cuzco por los comerciantes de Chincha ni por los chancas, ¿cómo, cuándo y de dónde llegó allí? ¿Su utilización por los incas se remonta solamente a la fase final de su expansión imperial? ¿O su arraigo en el Cuzco es mucho más antiguo? La primera hipótesis, que ha sido formulada por R. Cerrón-Palomino (2010: 269), implicaría que la base geográfica de la lengua vehicular del Tahuantinsuyo no fue verdaderamente el Cuzco sino que los incas de la época imperial optaron por administrar su Estado por medio de otro idioma que el suyo, idioma con el que recién entrarían en contacto a partir del reinado de Pachacuti, conquistador de los chancas y otros pueblos supuestamente quechuahablantes. Esta tesis me parece tropezar con varias dificultades importantes.

9 Esta posibilidad, que deberá ser objeto de investigación, me ha sido sugerida por Alan Durston. 
La primera es que ninguna fuente histórica recoge el recuerdo indígena de un contacto tan reciente de los incas con el quechua. La segunda es que, si bien se detectan elementos al parecer no quechuas en los nombres de los primeros incas (por ej. mayta o yupangi) y de algunas instituciones fundamentales de la sociedad cuzqueña (por ej. panaka 'cabeza de linaje', cf. Itier, 2011b), los nombres de las divinidades incas y sus epítetos y adjetivos son todos de origen quechua (wiraqucha, illapa, chuqi-illa, inti, punchaw, pacha-yachachiq, etc.) y en algunos casos, como el de Viracocha, presentan una evolución formal y semántica local que sugiere que su uso por los incas tenía cierta profundidad histórica (Itier, 2013). La toponimia regional, por su parte, está profundamente marcada por el quechua, lo cual tampoco aboga a favor de una introducción tardía de este idioma en la zona.

Pero sobre todo, el proceso por el cual los habitantes de la región del Cuzco adquirieron el quechua puede entreverse a través del resultado de la evolución local de la lengua. Si bien el cuzqueño antiguo parece haber tenido una mayor influencia de la lengua particular de los incas y del aimara que la que se observa en el cuzqueño moderno, la impronta de estos sustratos en el léxico y la morfosintaxis del quechua cuzqueño no deja de ser relativamente débil. Aun en campos semánticos como los de la fauna, la flora y las herramientas, es decir aquellos en que más suele manifestarse la influencia léxica de los sustratos, el dialecto cuzqueño contiene pocos términos que no sean de origen quechua. Los particularismos léxicos del quechua cuzqueño antiguo con respecto al cuzqueño moderno y a otras variedades de la familia lingüística parecen incluso haber sido predominantemente de origen quechua (por ej. ranaku- 'vender', minchi'contratar', minni- 'en ayunas', cf. Itier, 2012: LVI-LVII) y solo secundariamente aimara y de otra lengua. El hecho de que la(s) lengua(s) que hablaban los incas antes de adoptar el quechua no contribuyeran de manera muy notable al léxico del dialecto cuzqueño —con la excepción de los términos de parentescosugiere que estos idiomas no gozaban de mucho prestigio social o político frente al quechua en la época en que este idioma empezó a ser aprendido por los habitantes de las región. De la escasa influencia de la(s) lengua(s) de sustrato en la morfosintaxis del quechua cuzqueño, se puede inferir que los «Cuzcos» tuvieron la posibilidad de lograr un dominio muy grande de la lengua que adquirieron, lo que sugiere a su vez un contacto estrecho y prolongado con hablantes de esta última ${ }^{10}$. Es muy poco plausible que esta asimilación pudiera darse con tal grado de perfección si los incas recién hubieran adoptado el quechua después de las

10 Entre las innovaciones morfológicas del quechua cuzqueño que se pueden atribuir a la influencia del aimara, las más notables me parecen ser el empleo del orientador actancial -pu-para expresar un cambio de estado (chaypi tiyapun 'se quedó a vivir ahí'), sobre el modelo del uso del sufijo equivalente -xa- en aimara; la combinación del restrictivo -lla y del contrastivo -taq para expresar identidad (paypas hamullanqataqmi 'él también vendrá'), exactamente como lo hace el sufijo aimara -raki que también consta etimológicamente de un sufijo restrictivo (-ki); la creación de un tematizador interrogativo -ri (imataq chayri? '¿qué es eso?' donde -ri procede tal vez de la partícula ari 'pues') sobre el modelo del sufijo -sti de idéntico valor en aimara. Como se observa, se trata de innovaciones relativamente superficiales o secundarias. 
conquistas de Pachacuti, en un contexto en el cual habrían sido los vencedores de los hablantes de esa lengua.

Las mayores interferencias entre por lo menos una de las lenguas de sustrato y la lengua meta se produjeron a nivel fonológico, dando lugar a la adquisición de los rasgos glotal y aspirado del aimara por el quechua de la región del Cuzco. La única situación en que los estudios sobre contactos lingüísticos han observado que importantes interferencias fonológicas no corren pareja con influencias morfosintácticas y léxicas muy significativas es aquella en la cual la lengua meta es adquirida como segunda lengua por el sector superior de una sociedad aislada de la mayor parte de los hablantes de dicha lengua. Los nuevos hablantes de la lengua meta tienden entonces a reproducirla mucho más fielmente en su léxico y su morfosintaxis que en su fonología, como se observa en el caso del inglés hablado en la India por los indios (Grey Thomason \& Kaufman, 1991: 128-129). Tal vez debamos imaginar para la difusión del quechua hacia el Cuzco un proceso análogo al que implantó el inglés en la India: una colonización del país (la región de Cuzco) por un pueblo venido de lejos (los huaris) seguida del aprendizaje de la lengua de los colonizadores (el quechua) por las clases superiores de la sociedad local (los incas).

Concuerdo con Willem Adelaar (2010) y Paul Heggarty \& David G. Beresford-Jones (2010) en que, en el estado actual de nuestros conocimientos, el imperialismo huari es el candidato más plausible para explicar la introducción del quechua en la región del Cuzco. En base a las observaciones generales que preceden, formularé la hipótesis según la cual los incas aprendieron el quechua durante el Horizonte Medio, de boca de sus vecinos huaris de las cuencas de Lucre y Huaro, reproduciendo fielmente - menos en lo fonológico- el prestigioso idioma de los colonos ayacuchanos. Durante siglos, la lengua particular de los incas permanecería como idioma de los sectores inferiores de la sociedad, con poco prestigio, dejando su impronta en la vieja onomástica real y en los términos que designaban las instituciones sociales más tradicionales del Cuzco. Tal vez solo en la época imperial el bilinguismo lengua particular-quechua se generalizaría dentro de la sociedad inca. Los profundos cambios traídos por la colonización española acabarían finalmente tanto con la lengua local como con muchas particularidades del quechua tal como lo hablaban los incas. El hecho de que estos empezaran a construir un Estado regional inmediatamente después de la caída del imperio huari y que la lengua en la que se dio este proceso pareciera haber sido el quechua y no la «lengua particular» de los incas, sugiere que estos reutilizaron una lengua que ya tenía esa función integradora durante el período anterior, es decir el Horizonte Medio.

De la desintegración del sistema de comunicación prehispánico y del aprendizaje masivo de la «lengua del inca» de parte de la población indígena, emergería el idioma al cual los españoles solían referirse, en la época colonial, como a «la lengua general (del Cuzco)». Esta expresión designaba a mi entender un conjunto de variedades regionales herederas del cuzqueño antiguo, transformado de diversas maneras en las regiones por las cuales se había propagado (Itier, 2011a; 
2012). El quechua cuzqueño moderno, que aparece plenamente constituido hacia mediados del siglo XVII, es uno de los productos de esta metamorfosis, al parecer junto con los dialectos de Ecuador, Ayacucho, el Collao o Charcas. En efecto, la credibilidad de la que ha gozado la tesis del quechua costeño ha impedido tomar en consideración las aserciones presentes en múltiples fuentes históricas según las cuales la variedad de quechua hablada por los incas fue la fuente principal de dichas formas de quechua, es decir de lo que hoy llamaríamos «el conjunto dialectal quechua II». En trabajos posteriores examinaré las evidencias históricas, filológicas y lingüísticas que me llevan a pensar que la base de los dialectos ecuatorianos fue el cuzqueño antiguo, con importantes aportes lexicales introducidos por los colonos que los incas trajeron del centro y norte del Perú. Todo sugiere asimismo que el quechua ayacuchano fue el producto de la «cuzqueñización» de dialectos cercanos a los que se hablan actualmente en el centro del Perú.

\section{Referencias citadas}

ADELAAR, W. F. H., 2010 - Trayectoria histórica de la familia lingüística quechua y sus relaciones con la familia lingüística aimara. Boletín de Arqueología PUCP, 14: 239254.

ALBORNOZ, C. de, 1967 [ca 1580] - Instrucción para descubrir todas las huacas del Pirú y sus camayos y haciendas. Journal de la Société des Américanistes, 56: 17-39.

ÁNGELES FALCÓN, R., 2010 - Algunos aspectos de la ocupación inca en la costa central: de Paramonga a Cañete. Inka Llaqta, 1: 143-172.

ANÓNIMO, 1968 [1539] - Relación del sitio del Cuzco. In: Biblioteca peruana, t. III: 513612; Lima: Editores Técnicos Asociados S.A.

BAUER, B. S., 2004 - Ancient Cuzco: Heartland of the Inca, 255 pp.; Austin: University of Texas Press.

BAUER, B. S. \& COVEY, R. A., 2002 - Processes of state formation in the Inca heartland (Cuzco, Peru). American Anthropologist, 104 (3): 846-864.

BAUER, B. S., KELLETT, L. C. \& ARÁOZ SILVA, M., 2010 - The Chanka. Archaeological Reseach in Andahuaylas (Apurimac, Peru), 202 pp.; Los Ángeles: Corsen Institute of Archaeology Press, University of California.

BETANZOS, J. de, 1987 [1551] - Suma y narración de los incas, 317 pp.; Madrid: Atlas. Transcripción, notas y prólogo por M. del C. Martín Rubio.

CASTRO, C. de \& ORTEGA MOREJÓN, D. de, 1974 - Relación y declaración del modo que este valle de Chincha y sus comarcanos se gobernaban ántes que hobiese ingas y despues que los hobo. Historia y cultura, 8: 91-104.

CERRÓN-PALOMINO, R., 1987 - Lingüística quechua, 426 pp.; Cuzco: Centro Bartolomé de Las Casas.

CERRÓN-PALOMINO, R., 1989 - Lengua y sociedad en el valle del Mantaro, 138 pp.; Lima: Instituto de Estudios Peruanos.

CERRÓN-PALOMINO, R., 1990 - Reconsideración del llamado "quechua costeño". Revista Andina, 16 (2): 335-386 y 400-408. 
Las bases geográficas de la lengua vehicular del imperio inca

CERRÓN-PALOMINO, R., 1991 - Un texto desconocido del quechua costeño (s. XVI). Revista Andina, 18 (2): 393-413.

CERRÓN-PALOMINO, R., 2010 - Contactos y desplazamientos lingüísticos en los Andes centro-sureños: el puquina, el aimara y el quechua. Boletín de Arqueología PUCP, 14: 255-282.

CIEZA DE LEÓN, P., 1996 [1553] - Crónica del Perú, 238 pp.; Lima: Pontifica Universidad Católica del Perú, Academia Nacional de Historia. Edición. Prólogo y notas de F. Cantú.

CIEZA DE LEÓN, P., 2005 [1553] - Crónica del Perú. El señorío de los Incas, 497 pp.; Caracas: Biblioteca Ayacucho. Selección, prólogo, notas, cronología y bibliografía [por] F. Pease.

COBO, B., 1956 [1653] - Historia del Nuevo Mundo, 2 vols.; Madrid: Atlas, B.A.E. Estudio preliminar y edición del P. F. Mateos.

COOK, N. D., 2010 - La catástrofe demográfica andina. Perú 1520-1620, 416 pp.; Lima: Pontificia Universidad Católica del Perú.

COVEY, A., 2006 - How the Incas Built Their Heartland: State Formation and the Innovation of Imperial Strategies in the Sacred Valley, Peru, 352 pp.; Ann Arbor: University of Michigan Press.

DE LA BANDERA, D., 1968 [1557] - Relación del origen é gobierno que los Ingas tuvieron y del que había antes que ellos señoreasen á los indios deste reino... In: Biblioteca peruana, t. III: 491-510; Lima: Editores Técnicos Asociados S. A.

DUVIOLS, P., 1962 - Les sources religieuses du chroniqueur péruvien Fray Martin de Morúa. Annales de la Faculté des Lettres d'Aix, XXXVI: 267-277.

ESPINOSA SORIANO, W., 1973 - Colonias de mitmas múltiples en Abancay, siglos XV y XVI. Revista del Museo Nacional, XXXIX: 225-299.

ESTETE, M. de, 1968 - Noticia del Perú (hacia 1535). In: Biblioteca peruana, t. I: 345-402; Lima: Editores Técnicos Asociados S.A.

FORNEE, N. de, 1965 [1586] - Descripción de la tierra del corregimiento de Abancay. In: Relaciones Geográficas de Indias - Perú (M. Jiménez de la Espada, ed.), t. II: 16-30; Madrid: Atlas.

GARCILASO DE LA VEGA, 1959 [1617] - Historia general del Perú, segunda parte, 2 t., 882 pp.; Lima: Librería Internacional del Perú, S. A.

GARRETT, D. T., 2005 - Shadows of Empire. The Indian Nobility of CusCo, 1750-1825, 300 pp.; New York: Cambridge University Press.

GONZALEZ DE LA ROSA, M., 1911 - Origen costeño del Quechua. Ilustración peruana, n. ${ }^{\circ}$ 95, 26 de julio: 1208-1209.

GONZÁLEZ HOLGUÍN, D., 1607 - Gramatica y arte nveva de la lengva general de todo el Peru, Ilamada lengua Qquichua, o lengua del Inca, 144 ff.; Lima: Francisco del Canto.

GONZÁLEZ HOLGUíN, D., 1608 - Vocabvlario de la lengva general de todo el Perv llamada Qquichua, o del Inca, 375 ff.; Lima: Francisco del Canto.

GREY THOMASON, S. \& KAUFMAN, T., 1991 - Language Contact, Creolization and Genetic Linguistics, 411 pp.; Berkeley: University of California Press.

GUAMAN POMA DE AYALA, F., 1936 [1615] - Nueva corónica y buen gobierno, xxviii + 1168 S.; París: Institut d'Ethnologie.

HARTMANN, R., 1979 - ¿Quechuismo preincaico en el Ecuador? Ibero-Amerikanisches Archiv: Zeitschrift des Ibero-Amerikanischen Forschungs-Instituts der Universität Bonn: 267-299; Berlin. 
HEGGARTY, P. \& BERESFORD-JONES, D. G., 2010 - Archaeology, Language, and the Andean Past: Principles, Methods, and the New 'State of the Art'. Boletín de Arqueología PUCP, 14: 29-60.

HOCQUENGHEM, A. M., 1993 - Rutas de entrada del mullu en el extremo norte del Perú. Bulletin de l'Institut Français d'Études Andines, 22 (3): 701-719.

HOCQUENGHEM, A. M., 2012 - How did Quechua Reach Ecuador? In: Archaeology and Language in the Andes. A Cross-Disciplinary Exploration of Prehistory (P. Heggarty \& D. Beresford-Jones, eds.): 345-371; Nueva York: Oxford University Press.

ITIER, C., 2008 - Les Incas, 209 pp.; París: Les Belles Lettres.

ITIER, C., 2011a - What was the lengua general of Colonial Peru? In: History and Linguistics in the Andes (A. Pearce \& P. Heggarty, eds.): 63-85; London: Institute for the Study of the Americas, Palgrave.

ITIER, C., 2011b - Las panacas no existieron. In: Estudios sobre lenguas andinas y amazónicas. Homenaje a Rodolfo Cerrón-Palomino (W. F. H. Adelaar, P. Valenzuela Bismarck \& R. Zariquiey Biondi, eds.): 181-193; Lima: PUCP.

ITIER, C. 2012 [1631] - Juan Pérez Bocanegra y el Ritual formulario. In: Juan Pérez Bocanegra, Ritval formvlario e institvcion de curas, para administrar a los naturales de este reyno...: 49-72; Cuzco: Universidad Nacional de San Antonio Abad. Edición facsimilar.

ITIER, C. 2013 - Viracocha o el Océano, naturaleza y funciones de una divinidad andina, 91 pp.; Lima: Institut Français d'Études Andines, Instituto de Estudios Peruanos.

LANDERMAN, P. N., 1982 - Las sibilantes castellanas, quechuas y aymaras (un enigma tridimensional). In: Aula Quechua (R. Cerrón-Palomino, ed.): 203-234; Lima: ediciones Signo.

LOHMANN VILLENA, G., 1966 - Una nota acerca de curiosos paralelismos y correspondencias entre cuatro documentos históricos sobre la época incaica. Fénix, 16: 174-197.

MC EWAN, G., CHATFIELD, M. \& GIBAJA, A., 2002 - The Archaeology of Inca Origins. Excavations at Chokepukio, Cuzco, Peru. In: Andean Archaeology I. Variations in Sociopolitical Organization (W. H. Isbell \& H. Silverman, eds.): 287-301; Nueva York: Kluwer Academic, Plenum Publishers.

MANNHEIM, B., 1991 - The Language of the Inka since the European Invasion, 326 pp.; Austin: University of Texas Press.

MOGROVEJO, T., 2006 - Libro de visitas de Santo Toribio Mogrovejo (1593-1605), 458 pp.; Lima: Pontifica Universidad Católica del Perú. Introducción, transcripción y notas de J. A. Benito.

MURÚA, M. de, 1987 - Historia general del Perú, 583 pp.; Madrid: Historia 16. Edición de M. Ballesteros.

PARKER, G. J., 1963 - La Clasificación Genética de los Dialectos Quechuas. Revista del Museo Nacional, XXXII: 241-252.

PIZARRO, H., 1968 [1533] - Carta. In: Biblioteca peruana, t. I: 117-130; Lima: Editores Técnicos Asociados S.A.

PORRAS BARRENECHEA, R., 1959 - Cartas del Perú (1524-1543), 562 pp.; Lima: Edición de la Sociedad de Bibliófilos Peruanos.

RAMOS, G., 2010 - Muerte y conversión en los Andes. Lima y Cuzco, 1532-1670, 362 pp.; Lima: Instituto de Estudios Peruanos, Cooperación Regional Francesa para los Países Andinos, Instituto Francés de Estudios Andinos. 
RAMOS, G., 2011 - Language and Society in Early Colonial Peru. In: History and Language in the Andes (P. Heggarty \& A. J. Pearce, eds.): 19-38; Nueva York: Palgrave Macmillan.

RIVERA SERNA, R., 1965 - Libro primero de cabildos de la ciudad del Cuzco, 44 pp.; Lima: Universidad Nacional Mayor de San Marcos.

ROMERO, C. A., 1928 - Un libro interesante. Revista Histórica, IX (1): 53-87.

ROSTWOROWSKI DE DIEZ CANSECO, M., 1977 [1970] - Mercaderes del valle de Chincha en la época prehispánica: un documento y unos comentarios. In: Etnía y sociedad. Costa peruana prehispánica (M. Rostworowski, ed.): 97-140; Lima: Instituto de Estudios Peruanos. Publicado primero en Revista Española de Antropología Americana, 1970, 5.

ROWE, J. H., 2003a - La mentira literaria en la obra de Martín de Murúa. In: Los Incas del Cuzco. Siglos XVI-XVII-XVIII (J. H. Rowe, ed.): 127-134; Cuzco: Instituto Nacional de Cultura.

ROWE, J. H., 2003b - Probanza de los incas nietos de conquistadores (1569). In: Los Incas del Cuzco. Siglos XVI-XVII-XVIII (J. H. Rowe, ed.): 79-116; Cuzco: Instituto Nacional de Cultura.

SALOMON, F. \& GROSBOLL, S., 2011 - A visit to the Children of Chaupi ñamca: From Myth to History via Onomastics and Demography. In: History and Linguistics in the Andes (A. Pearce \& P. Heggarty, eds.): 39-61; London: Institute for the Study of the Americas, Palgrave.

SANCHO, P., 1962 [1534] - Relación de la conquista del Perú escrita por..., 106 pp.; Madrid: Ediciones José Porrua Turanzas. Versión castellana con anotaciones por Joaquín García Icazbalceta.

SANDWEISS, D. H., 1992 - The Archaeology of Chincha Fishermen: Specialization and Status in Inka Peru. Carnegie Museum of Natural History Bulletin, 29 (9): 161 pp.; Pittburgh.

SANTO TOMÁS, D. de, 1951a - Lexicon, o Vocabulario de la lengua general del Perv..., 374 pp.; Lima: Universidad Nacional Mayor de San Marcos. Edición facsimilar publicada, con un prólogo, por Raúl Porras Berrenechea

SANTO TOMÁS, D. de, 1951b - Grammatica. o arte de la lengua general de los Indios de los Reynos del Peru, 207 pp.; Lima: Universidad Nacional Mayor de San Marcos. Edición facsimilar publicada, con un prólogo, por Raúl Porras Barrenechea.

SILVA Y GUZMAN, D. de, 1968 [1538] - La crónica rimada. In: Biblioteca peruana, t. I: 17-115; Lima: Editores Técnicos Asociados S.A.

TAYLOR, G., 1994 - Estudios de dialectología quechua (Chachapoyas, Ferreñafe, Yauyos), 203 pp.; Lima: Ediciones Universidad Nacional de Educación.

TAYLOR, G., 2000 - Lengua general y lenguas particulares en la antigua provincia de Yauyos. Un documento quechua de Huarochirí - 1608. In: Camac, camay y camasca y otros ensayos sobre Huarochirí y Yauyos (G. Taylor, ed.): 35-69; Lima: Institut Français d'Études Andines, Centro Bartolomé de Las Casas.

TERCER CONCILIO DE LIMA, 1584 - Doctrina Christiana, y catecismo para instrvccion de los Indios..., 785 pp.; Lima : Antonio Ricardo.

TORERO, A., 1964 - Los dialectos quechuas. Anales Científicos de la Universidad Agraria, 2: $446-478$.

TORERO, A., 1974 - El quechua y la historia social andina, 241 pp.; Lima: Universidad Ricardo Palma.

TORERO, A., 1984 - El comercio lejano y la difusión del quechua: el caso del Ecuador. Revista Andina, 4 (2): 367-389. 
TORERO, A., 2002 - Idiomas de los Andes - Lingüística e Historia, 565 pp.; Lima: Editorial Horizonte, Institut Français d'Études Andines.

TRUJILLO, D. de, 1968 [1571] - Relación del descubrimiento del reyno del Peru. In: Biblioteca peruana, t. II: 9-103; Lima: Editores Técnicos Asociados S.A.

XEREZ, F. de, 1891 [1534] - Verdadera Relación de la Conquista del Perú, 167 pp.; Madrid. 